\title{
Vibrational Properties of Hydrogen Astatide, HAt
}

\author{
Enrique J. Baran \\ Centro de Química Inorgánica (CEQUINOR/CONICET, UNLP), Facultad de Ciencias Exactas, \\ Universidad Nacional de La Plata, C. Correo 962, 1900-La Plata, Argentina
}

Reprint requests to Prof. Dr. E.J.B.; Fax: (54) 0221 4259485; E-mail: baran@quimica.unlp.edu.ar

Z. Naturforsch. 59a, 133 - 135 (2004); received January 8, 2003

\begin{abstract}
A number of theoretical studies on the bond characteristics of HAt, the heaviest hydrogen halide, have recently been reported. On the basis of these data the force constant, mean amplitudes of vibration and thermodynamic functions of this molecule have been calculated. Some comparisons with the related lighter hydracids are made.
\end{abstract}

Key words: HAt; Force Constant; Mean Amplitudes of Vibration; Thermodynamic Functions.

Astatine $(Z=85)$ is the heaviest member of the elements of group 17 of the Periodic System (halogens). About 20 isotopes are known, and some of them have been identified as short-lived products in the natural radioactive series. The longest-lived isotope is ${ }^{210} \mathrm{At}$ with a half-life of only 8.3 hours. Consequently, macroscopic quantities of this element cannot be accumulated. Our knowledge on its chemistry is mainly based on tracer studies, which show that it behaves in the manner one would expect, by extrapolation from the other halogens [1,2].

Hydrogen astatide, HAt, is therefore the heaviest hydrogen halide. Although its formation has been detected mass spectroscopically [1], no other experimental studies on its physical and chemical behavior could be undertaken. Notwithstanding, in recent years a number of theoretical studies, has been performed on this molecule [3-5]. Therefore, it seems interesting to explore with more detail its vibrational properties and to establish correlations with the other hydrogen halides.

The bond distance, dissociation energy and harmonic frequency for HAt have been calculated on the basis of different theoretical frameworks and at different degrees of sophistication, using relativistic and non-relativistic approaches [3 -5]. For most of our purposes the knowledge of the harmonic frequency is of central importance. A thorough analysis of the available data shows that the most reasonable values lie between 2155 and $2185 \mathrm{~cm}^{-1}$ [3-5]. Force constants calculated with these two extreme figures only differ by about $3 \%$. Thus, in all the calculations we have used

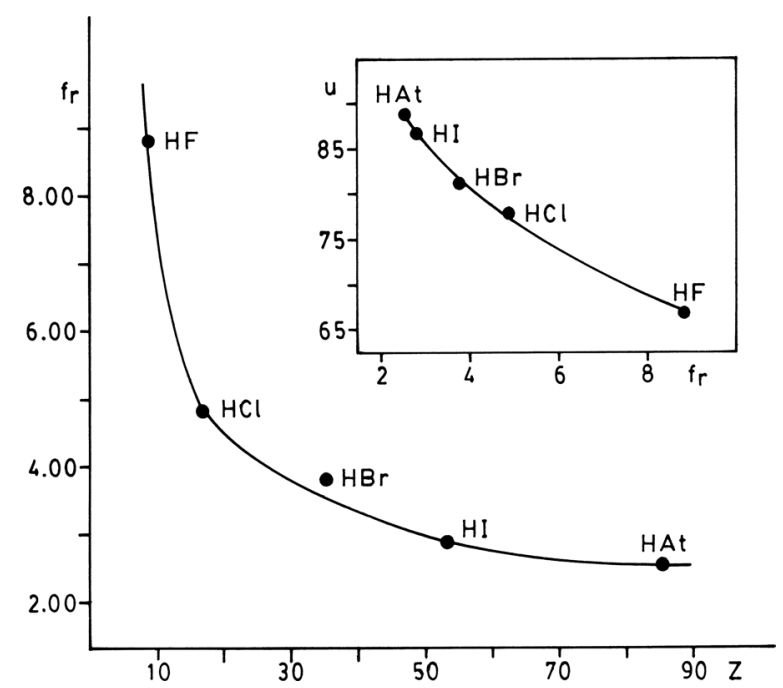

Fig. 1. H-X force constant $f_{\mathrm{r}}$ (in mdyn/ $/$ ) for the hydrogen halides as a function of the atomic number $(Z)$ of the halogen atom. Inset: Mean amplitudes of vibration $(u) \times 10^{3}$ (in $\AA$, at $298.16 \mathrm{~K}$ ) as a function of the force constants $f_{\mathrm{r}}$ (in mdyn/A) of the hydrogen halides.

the value of $2155 \mathrm{~cm}^{-1}$ for the stretching frequency of the H-At bond. The corresponding bond length can be estimated to lie at about $1.70 \AA$. For the atomic mass of At, a value of 209.9871 [5] has been used in all the performed calculations.

Using the mentioned harmonic frequency and the well-known "two-masses model" [6] a value of $2.74 \mathrm{mdyn} / \AA$ can be calculated for the force constant of the H-At bond. As can be seen from Fig. 1 this value correlates very well with those corresponding to the 
Table 1. Mean amplitudes of vibration (in $\AA$ ) for the hydrogen halides in the temperature range between 0 and $1000 \mathrm{~K}$.

\begin{tabular}{cccccc}
\hline$T(\mathrm{~K})$ & $\mathrm{HF}$ & $\mathrm{HCl}$ & $\mathrm{HBr}$ & $\mathrm{HI}$ & HAt \\
\hline 0 & 0.0668 & 0.0772 & 0.0813 & 0.0870 & 0.0883 \\
100 & 0.0668 & 0.0772 & 0.0813 & 0.0870 & 0.0883 \\
200 & 0.0668 & 0.0772 & 0.0813 & 0.0870 & 0.0883 \\
298.16 & 0.0668 & 0.0772 & 0.0813 & 0.0870 & 0.0883 \\
300 & 0.0668 & 0.0772 & 0.0813 & 0.0870 & 0.0883 \\
400 & 0.0668 & 0.0772 & 0.0813 & 0.0870 & 0.0883 \\
500 & 0.0668 & 0.0772 & 0.0814 & 0.0871 & 0.0885 \\
600 & 0.0668 & 0.0773 & 0.0815 & 0.0874 & 0.0888 \\
700 & 0.0668 & 0.0774 & 0.0818 & 0.0879 & 0.0894 \\
800 & 0.0668 & 0.0776 & 0.0822 & 0.0886 & 0.0901 \\
900 & 0.0669 & 0.0780 & 0.0827 & 0.0895 & 0.0912 \\
1000 & 0.0670 & 0.0784 & 0.0834 & 0.0906 & 0.0924 \\
\hline
\end{tabular}

Table 2. $v(\mathrm{H}-\mathrm{X})$ stretching frequencies $\left(\mathrm{cm}^{-1}\right)$, force constants (mdyn/ $/$ ) and mean amplitudes of vibration $(\AA)$ at $298.16 \mathrm{~K}$ for the hydrogen halides.

\begin{tabular}{lccccc}
\hline \multicolumn{7}{c}{ HF } & HCl & HBr & HI & HAt \\
\hline$v(\mathrm{H}-\mathrm{X})^{*}$ & 3961 & 2886 & 2559 & 2227 & 2155 \\
$f(\mathrm{H}-\mathrm{X})^{*}$ & 8.87 & 4.81 & 3.84 & 2.92 & 2.74 \\
$u(\mathrm{H}-\mathrm{X})$ & 0.0668 & 0.0772 & 0.0813 & 0.0870 & 0.0883 \\
\hline * all values, except those for HAt, from [7]. & &
\end{tabular}

other four hydrogen halides $(\mathrm{HF}=8.87 ; \mathrm{HCl}=4.81$; $\mathrm{HBr}=3.84 ; \mathrm{HI}=2.92 \mathrm{mdyn} / \AA$ [7]).

The mean amplitudes of vibration at different temperatures have been calculated using the relations of Kimura and Kimura [8] (cf. also [9, 10]). Using this same methodology, and in order to allow a wider insight into the vibrational characteristics of this type of compounds, we have extended these calculations to the full series of hydrogen halides. The necessary vibrational frequencies were obtained from the book of Siebert [7]. The obtained results, in the temperature range between 0 and $1000 \mathrm{~K}$, are presented in Table 1.

As can be seen, these values show only a slight temperature dependence, as expected for bonds with $\omega>2000 \mathrm{~cm}^{-1}$ [11]. This dependence increases from HF to HAt, although even in this last case the increment is only $4.6 \%$ from absolute zero to $1000 \mathrm{~K}$.

In Table 2 we compare the X-H stretching frequencies, mean amplitudes of vibration and force constants for the complete series of hydrogen halides. This comparison shows the expected trend, i.e., mean amplitudes of vibration become higher when force constants becomes lower $[11,12]$. The inset of Fig. 1 presents the correlation between both values, which confirms
Table 3. Statistical thermodynamic functions of HAt, compared with that of HI (values in cal/deg.mole).

\begin{tabular}{ccccc}
\hline$T(\mathrm{~K})$ & $C_{\mathrm{p}}$ & $\left(H^{\mathrm{o}}-H_{\mathrm{o}}{ }^{\mathrm{o}}\right) / T$ & $-\left(G^{\mathrm{o}}-G_{\mathrm{o}}{ }^{\mathrm{o}}\right) / T$ & $S^{\mathrm{o}}$ \\
\hline 100 & 7.95 & 7.95 & 40.08 & 48.03 \\
200 & 7.95 & 7.95 & 45.59 & 53.54 \\
298.16 & 7.96 & 7.95 & 48.76 & 56.71 \\
300 & 7.96 & 7.95 & 48.81 & 56.76 \\
400 & 8.00 & 7.96 & 51.10 & 59.06 \\
500 & 8.10 & 7.97 & 52.88 & 60.85 \\
600 & 8.25 & 8.01 & 54.33 & 62.34 \\
700 & 8.43 & 8.06 & 55.57 & 63.63 \\
800 & 8.59 & 8.11 & 56.65 & 64.76 \\
900 & 8.75 & 8.17 & 57.61 & 65.79 \\
1000 & 8.89 & 8.24 & 58.48 & 66.72 \\
1100 & 9.01 & 8.30 & 59.26 & 67.57 \\
1200 & 9.12 & 8.37 & 59.99 & 68.36 \\
1300 & 9.21 & 8.43 & 60.66 & 69.09 \\
1400 & 9.29 & 8.49 & 61.29 & 69.78 \\
1500 & 9.36 & 8.54 & 61.88 & 70.42 \\
Comparison with HI values, at some selected temperatures: \\
100 & 7.95 & 7.95 & 38.24 & 46.19 \\
298.16 & 7.95 & 7.95 & 46.93 & 54.88 \\
500 & 7.97 & 7.97 & 51.04 & 59.01 \\
700 & 8.39 & 8.04 & 53.73 & 61.77 \\
1000 & 8.85 & 8.22 & 56.63 & 64.85 \\
1200 & 9.08 & 8.34 & 58.14 & 66.48 \\
1500 & 9.33 & 8.52 & 60.02 & 68.54 \\
\hline
\end{tabular}

the excellent correlation of all of them and additionally confirms that HAt behaves in the expected manner.

Finally, we have also calculated the thermodynamic functions for HAt, in a wide temperature range, for the ideal gaseous state (unit fugacity) using the rigid rotator, harmonic oscillator approximation $[13,14]$. The symmetry number is 1 . The results, specific heat $\left(C_{\mathrm{p}}\right)$, reduced enthalpy $\left[\left(H^{0}-H_{0}{ }^{0}\right) / T\right]$, reduced free enthalpy $\left[\left(G^{0}-H_{0}{ }^{0}\right) / T\right]$ and entropy $\left(S^{0}\right)$, in the temperature range between 100 and $1500 \mathrm{~K}$, are presented in Table 3.

For comparative purposes similar calculations were performed for the closely related hydrogen iodide molecule. Values obtained at some selected temperatures are also shown in Table 3. As it can be seen, these values are comparable, and only slightly lower, than those obtained for HAt.

\section{Acknowledgements}

This work was supported by the "Consejo Nacional de Investigaciones científicas y Técnicas de la República Argentina". The author is a member of the Research Career of this organism. 
[1] F. A. Cotton, G. Wilkinson, C. Murillo, and M. Bochmann, Advanced Inorganic Chemistry, $6^{\text {th }}$ Ed., J. Wiley \& Sons, New York 1999.

[2] N. N. Greenwood and A. Earnshaw, Chemistry of the Elements, $2^{\text {nd }}$ Ed., Butterworth-Heinemann, Oxford 1997.

[3] M. Dolg, Mol. Phys. 88, 1645 (1996).

[4] E.P.F. Lee and T. G. Wright, Chem. Phys. Lett. 331, 533 (2000).

[5] J. Styszynski and J. Kobus, Chem. Phys. Lett. 369, 441 (2003).

[6] A. Fadini and F.M. Schnepel, Schwingungsspektroskopie: Methoden, Anwendungen, G. Thieme Verlag, Stuttgart 1985.

[7] H. Siebert, Anwendungen der Schwingungsspektro- skopie in der Anorganischen Chemie, Springer Verlag, Berlin 1966.

[8] K. Kimura and M. Kimura, J. Chem. Phys. 25, 362 (1956).

[9] E. J. Baran, Z. Physik. Chem. 255, 1022 (1974).

[10] E. J. Baran, Z. Naturforsch. 58a, 36 (2003).

[11] S. J. Cyvin, Molecular Vibrations and Mean Square Amplitudes, Elsevier, Amsterdam 1968.

[12] A. Müller, E. J. Baran, and K.H. Schmidt, in S. J. Cyvin (Ed.), Molecular Structures and Vibrations, Elsevier, Amsterdam 1972, pp. 376-391.

[13] K. S. Pitzer, Quantum Chemistry, Prentice Hall, New Jersey 1953.

[14] G. Allen and H. O. Pritchard, Statistical Mechanics and Spectroscopy, Butterworths, London 1974. 